\title{
PENGARUH COST SAVING, TIME SAVING DAN TRUST TERHADAP \\ PURCHASE INTENTION MELALUI PERCEIVED VALUE PADA KONSUMEN \\ (Studi kasus: Minuman Tradisional Wedang Uwuh di Imogiri Bantul Yogyakarta)
}

\author{
Ilya Nafilah ${ }^{-}$ \\ Universitas Sarjanawiyata Tamansiswa Yogyakarta \\ e-mail : Ilyanflh@gmail.com \\ I Bagus Nyoman U \\ Universitas Sarjanawiyata Tamansiswa Yogyakarta \\ e-mail : Ibn.udayana@yahoo.co.id \\ A Lukitaningsih \\ Universitas Sarjanawiyata Tamansiswa Yogyakarta \\ e-mail : ambaryudono@yahoo.com
}

\begin{abstract}
This study aims to determine the effect of cost saving, time saving and trust on purchase intention through perceived value. This research was conducted on consumers of Wedang Uwuh Beverage in Imogiri Bantul Yogyakarta. The results of this study indicate: 1) Cost Saving has a significant positive effect on Perceived Value, 2) Cost Saving has a significant positive effect on Purchase Intention, 3) Time Saving has a significant positive effect on Perceived Value, 4) Time Saving has a significant positive effect on Purchase Intention, 5 ) Trust has a significant positive effect on Perceived Value, 6) Trust has no significant positive effect on Purchase Intention, 7) Perceived Value has a significant positive effect on Purchase Intention.
\end{abstract}

\begin{abstract}
ABSTRAK
Penelitian ini bertujuan untuk mengetahui pengaruh penghematan biaya, penghematan waktu dan kepercayaan terhadap niat beli melalui nilai yang dipersepsikan. Penelitian ini dilakukan pada konsumen Minuman Wedang Uwuh Imogiri Bantul Yogyakarta. Hasil penelitian ini menunjukkan: 1) Cost Saving berpengaruh positif signifikan terhadap Perceived Value, 2) Cost Saving berpengaruh positif signifikan terhadap Purchase Intention, 3) Time Saving berpengaruh positif signifikan terhadap Perceived Value, 4) Time Saving memiliki pengaruh positif signifikan terhadap Niat Beli, 5) Kepercayaan berpengaruh positif signifikan terhadap Perceived Value, 6) Kepercayaan tidak berpengaruh positif signifikan terhadap Niat Beli, 7) Perceived Value berpengaruh positif signifikan terhadap Niat Beli.
\end{abstract}

Kata Kunci : Penghematan Biaya, Penghematan Waktu, Kepercayaan, Niat Membeli, Nilai Persepsi 


\section{PENDAHULUAN}

Kenaikan pertumbuhan bisnis minuman menunjukkan bahwa berbisnis di sektor minuman lumayan menjanjikan. Peluang usaha yang berkaitan dengan industri minuman memang memiliki prospek yang cukup bagus dan relatif lebih mudah untuk memulai suatu bisnis minuman dibanding dengan bisnis lainnya. Selain itu kemajuan dunia kuliner terutama di kota-kota besar semakin pesat dan menjadi tren, sehingga membuat orang ingin mendirikan sebuah bisnis yang berhubungan dengan penyediaan minuman.

Masyarakat Indonesia kaya tradisi salah satu minuman Wedang Uwuh yang merupakan salah satu minuman asli para raja (Yogyakarta). 'Wedang' dalam bahasa Jawa berarti minuman, 'Uwuh' dalam bahasa Jawa berarti sampah (sampah yang dimaksud adalah sampah dedaunan). Wedang Uwuh bila diartikan langsung berarti Minuman Sampah, tapi ini hanyalah istilah saja. Wedang uwuh terdiri dari daun pala yang diambil dari guguran daun pala di makam Raja-raja Mataram, daun cengkeh, kayu secang dan rimpang jahe. Resep yang disajikan secara turun temurun ini dulu dikenal dengan nama wedang jahe cengkeh. Minuman ini biasa disajikan dengan cara diseduh dengan air panas lalu ditambah dengan gula batu dan dinikmati panas-panas. Selain enak, minuman ini juga menyehatkan. Menurut kepercayaan penduduk setempat, minuman ini memiliki khasiat yang dapat menyembuhkan batuk ringan, loyo-loyo, pegal-pegal, perut kembung dan masuk angin.

Model penjualan wedang uwuh ini masih dapat dikatakan kurang dalam hal bisnis, karena penjualan masih berbasis tradisional dari produsen ke pasar. Sehingga kemampuan produk untuk mempunyai margin ekonomi di tingkat pasar luar daerah masih kurang. Tingkat penjualan sebenarnya mampu meningkat jika ekspansi pasar dilakukan dengan model baru sehingga tingkat ekonomi penjualan mampu maksimal tidak hanya berhenti disuatu pasar dengan keterbatasan akses.

Kemasan wedang uwuh yang beredar di masyarakat sangat sederhana, hanya berupa komponen kering yang dibungkus plastik. Setiap satu bungkus plastik wedang uwuh yang dijual dengan harga dua ribu rupiah dapat diseduh menjadi satu gelas besar. Wedang uwuh kemasan plastik ini dapat dibawa pulang dan dijadikan oleh-oleh. Sayangnya kemasan wedang uwuh ini kurang menarik, penyajiannya agak merepotkan dan tidak tahan disimpan dalam waktu yang agak lama, sehingga nilai ekonomi dari wedang uwuh kemasan plastik ini masih kurang relevan.

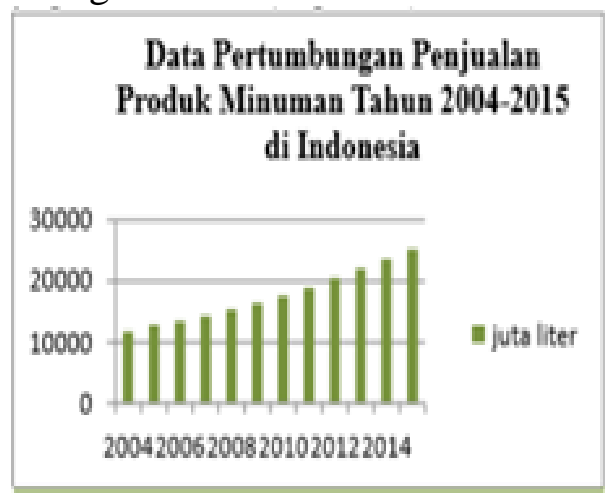

Gambar 1 Data Pertumbungan Penjualan Produk Minuman Tahun 2004-2015 di Indonesia

Pada data diatas dapat disimpulkan bahwa pertumbuhan penjualan minuman di Indonesia ringan terus meningkat dari tahun 2004-2015. Pertumbuhan industri minuman Wedang Uwuh yang begitu menjanjikan mendorong para perusahaan dari perusahaan 
besar sampai perusahaan kecil untuk terjun dalam industri ini dengan menjadi produsen minuman Wedang Uwuh, penyalur distribusi minuman Wedang Uwuh, maupun menjual minuman Wedang Uwuh kepada toko-toko kecil.

Efisiensi biaya produksi sangat memerlukan harga pokok produksi untuk memperhitungkan biaya yang nantinya akan dikeluarkan dalam proses produksi pesanan khusus dengan tepat. Salah satu metode yang dapat digunakan adalah variabel costing. Menurut Salman (2016), variabel costing yang juga dikenal dengan direct costing adalah biaya yang jumlah totalnya berubah secara proporsional sesuai dengan volume kegiatan atau produksi dan jumlah biaya per unitnya tidak mengalami perubahan. Bisnis prospek biaya harus mampu dipertimbangkan secara detail sehingga pangsa pasar mampu meningkat dengan biaya yang efisien dalam proses pemasaran di tingkat pasar produsen harus datang dan menyewa stand dipasar tingkat kemungkinan biaya dari segi transportasi, tenaga, dan kwantitas barang kurang maksimal.

Adebisi (2013), manajemen waktu secara singkat dapat diartikan sebagai suatu seni mengatur, mengorganisasi, menjadwalkan, serta menganggarkan waktu seseorang untuk menghasilkan kerja lebih efektif dan produktif. Waktu yang singkat mampu memproduksi atau menjual barang dengan cepat adalah keuntungan margin bagi pelaku sehingga grafik laba mampu maksimal dalam realita lapangan waktu penjualan banyak hilang dipasar menunggu konsumen datang membuang banyak waktu. Jika ada suatu metode penjualan yang maksimal mampu meningkatkan kualitas dan kwantitas.

Priansa (2017) Trust adalah sebuah harapan yang dipegang oleh individu atau sebuah kelompok ketika perkataan, janji, pernyataan lisan atau tulisan dari individu atau kelompok lainnya dapat diwujudkan. Menurut (Adi, 2013) trust dipertimbangkan sebagai dorongan dalam berbagai transaksi antara penjual dan pembeli agar kepuasan konsumen dapat terjadi sesuai yang diinginkan. Setelah konsumen mengkonsumsi produk minuman tradisional wedang uwuh dan menggunakannya secara nyata maka akan menimbulkan kepercayaan konsumen dan menimbulkan rasa puas. Setelah konsumen merasa puas terhadap suatu produk minuman tradisional wedang uwuh maka tidak akan dengan mudah meninggalkan dan berganti ke yang lainnya.

Purchase intention adalah sikap konsumen dalam membuat keputusan pembelian yang akan dilakukan (Fure, 2013). Keputusan dalam pembelian produk bermerek yang dilakukan konsumen memiliki alasan tertentu. Perilaku individu diprediksi dengan purchase intention dan hal penting dalam niat adalah intensitasnya (Wuryandari, 2014). Timbulnya purchase intention terhadap calon konsumen pada sebuah produk diakibatkan oleh pengaruh dari produk itu sendiri. Perusahaan harus berupaya menjaga purchase intention konsumen agar tertarik untuk membeli produk yang dijual oleh perusahaan atau calon konsumen yang akan membeli produk tersebut.

Perceived value merupakan suatu hal yang penting, karena apabila suatu produk tidak mampu menghasilkan nilai pada produk tersebut maka akan mudah diserang atau kalah dengan produk pesaingnya. Pemasar dapat meningkatkan nilai tawaran pelanggan dengan berbagai cara: meningkatkan manfaat, menurunkan biaya atau harga, meningkatkan manfaat lebih besar daripada kenaikan biaya, menurunkan manfaat lebih kecil daripada menurunkan biaya (Kotler dan Keller, 2012). Menurut (Tjiptono, 2005) memberikan definisi atau pengertian customer value (nilai pelanggan) sebagai ikatan emosional yang terjalin antara pelanggan dan produsen setelah pelanggan menggunakan produk dan jasa dari perusahaan dan mendapati produk atau jasa tersebut memberi nilai tambah. Berdasarkan penilaian diatas dapat disimpulkan bahwa perceived customer value merupakan penilaian konsumen yang dilakukan dengan cara membandingkan antara 
manfaat atau keuntungan yang akan diterima dengan pengorbanan yang dikeluarkan untuk memperoleh sebuah produk atau jasa. Nilai pelanggan dipandang sebagai penilaian konsumen secara keseluruhan dari manfaat produk wedang uwuh berdasarkan resepsi yang diterima dan diberikan. Penilaian ini dianggap sebagai perbandingan dari komponen produk wedang uwuh. Penelitian ini mengacu pada penelitian yang dilakukan oleh Tomas Escobar, (2016) dengan judul "Analysing Online Purchase Intention In Spain: Fashion E-Commerce". Hasil penelitian dinyatakan bahwa terdapat pengaruh signifikan variabel cost saving, time saving, dan trust terhadap purchase intention melalui perceived value. Saran yang diberikan kepada peneliti selanjutnya untuk meneliti atau melanjutkan penelitian ini. Maka peneliti meneliti pada konsumen yang mengkonsumsi.

Berkaitan dengan uraian tersebut diatas, maka peneliti akan melakukan penelitian dengan judul "pengaruh cost saving, time saving, dan trust terhadap purchase intention melalui perceived value pada konsumen (studi kasus minuman tradisional wedang uwuh di imogiri bantul yogyakarta)".

a. Cost Saving (CSAV)

Cost merupakan salah satu sumber informasi yang penting dalam analisis strategik perusahaan. Pada dasarnya masalah yang sering timbul adalah perencanaan biaya yang kurang sesuai dengan apa yang terjadi sesungguhnya (realisasi biaya). Oleh sebab itu untuk dapat mencapai produksi yang efisien, maka diperlukan pengendalian biaya produksi yang akan dikeluarkan. Biaya produksi merupakan biaya untuk mengolah bahan menjadi barang jadi. Biaya produksi industri terdiri dari biaya bahan, biaya tenaga kerja dan biaya overhead pabrik. Menekan biaya produksi merupakan suatu pengendalian biaya yang penting untuk dilakukan agar tidak terjadi pemborosan, dengan harus tetap memperhatikan kualitas produk yang dihasilkan. Meningkatkan kepuasan pelanggan dan dapat mempertahankan pangsa pasar dalam jangka panjang. Kemampuan perusahaan dalam menetapkan biaya produksi akan mempengaruhi tingkat laba yang diperoleh (Putu, 2014).

Bila suatu produk mengharuskan konsumen mengeluarkan biaya yang lebih besar dibanding manfaat yang diterima, maka yang terjadi adalah bahwa produk tersebut memiliki nilai negatif. Konsumen mungkin akan menganggap sebagai nilai yang buruk dan kemudian akan mengurangi konsumsi terhadap produk tersebut. Bila manfaat yang diterima lebih besar, maka yang terjadi adalah produk tersebut memiliki nilai positif (Lupiyoadi \& Hamdani, 2006). Menurut Sofyan Syafri Harahap (2011) terdapat 2 indikator yaitu biaya penjualan dan biaya umum dan administrasi.

b. Time Saving (TSAV)

Time adalah sumber yang unik, waktu tidak dapat ditabung tapi hanya dapat dipergunakan dengan bijaksana. Time yang sudah berlalu hilang selamanya, waktu tidak dapat diganti dan tidak elastis.

Manajemen waktu sebagai pengaturan diri individu dalam menggunakan waktu seefektif dan seefesien mungkin dengan melakukan perencanaan, penjadwalkan, pengontrolan waktu dan selalu membuat skala prioritas menurut kepentingannya serta keinginan untuk terorganisasi (Gasim, 2016).

Manajemen waktu bukan hanya mengacu kepada pengelolaan waktu, tetapi lebih cenderung pada bagaimana memanfaatkan waktu. Individu yang mampu mengelola waktu akan menentukan prioritas dari berbagai tugas yang dihadapi, fokus waktu dan energi pada tugas yang penting terlebih dahulu. Menurut Kartadinata (2008), indikator manajemen waktu adalah kemampuan mengendalikan waktu dan perencanaan. 
c. Trust (T)

Trust adalah suatu kesadaran dan perasaan yang dimiliki oleh pelanggan untuk mempercayai sebuah produk, dan digunakan penyedia jasa sebagai alat untuk menjalin hubungan jangka panjang dengan pelanggan (Diza, Moniharapon, \& Ogi, 2016). Menurut Norhermaya dan Soesanto (2016), membentuk kepercayaan pelanggan merupakan salah satu cara untuk menciptakan dan mempertahankan pelanggan. Kepercayaan yang tinggi oleh konsumen terhadap perusahaan akan dapat memberikan rasa puas konsumen dalam menggunakan produk atau jasa perusahaan, seperti Widiyanto yang menyatakan bahwa kepercayaan pelanggan merupakan pondasi dari bisnis yang merupakan cara untuk menciptakan dan mempertahankan konsumen (Laely, 2016).

Menurut Pappers dan Roggers (2004) faktor-faktor yang mempengaruhi trust antara lain: nilai, ketergantungan pada pihak lain mengimplikasikan kerentanan dan komunikasi yang terbuka dan teratur. Menurut Sukma Abdurrahman Adi (2012) indikator trust adalah jaminan kepuasan, perhatian dan keterus-terangan.

d. Purchase Intention (PI)

Purchasing Intention adalah suatu keinginan untuk membeli, yang merupakan bagian dari proses-proses untuk melakukan tindakan pembelian yang dilakukan oleh konsumen. Sebelum membeli konsumen mengumpulkan informasi produk berdasarkan pengalaman pribadi dan lingkungan eksternal (Ni Nyoman Kerti Yasa dan I Ketut Rahyuda, 2015).

Niat beli konsumen adalah tahap konsumen dalam membentuk pilihan diantara beberapa merek bergabung dalam perangkat pilihan, kemudian pada akhirnya melakukan suatu pembelian pada suatu alternatif yang paling disukainya atau proses yang dilalui konsumen untuk membeli suatu barang atau jasa yang didasari oleh bermacam pertimbangan (Annafik dan Rahardjo, 2012).

Konsumen yang memiliki Swastha dan Irawan (2011) mengemukakan faktor-faktor yang mempengaruhi minat beli berhubungan dengan perasaan dan emosi, bila seseorang merasa senang dan puas dalam membeli barang atau jasa maka hal itu akan memperkuat minat membeli, ketidakpuasaan biasanya menghilangkan minat.

e. Perceived Value (PV)

Perceived Value merupakan penukaran yang menjadi pokok dalam penasaran dengan nilai sebagai pengukur yang tepat dari penukaran apapun baik pantas maupun tidak (Kotler dan Keller, 2011). Customer perceived value adalah selisih antara penilain pelanggan prospektif atas semua manfaat dan biaya dari suatu penawaran terhadap alternatifnya. Jadi, produk dikatakan memiliki nilai yang tinggi jika sesuai dengan kebutuhan, keinginan, dan permintaan pelanggan (Kotler dan Keller, 2011).

Penjelasan indikator customer perceived value selanjutnya mengacu pada pendapat Tjiptono (2016), sebagai berikut:

1. Emotional value, yaitu manfaat yang diperoleh dari perasaan atau afektif/emosi positif yang ditimbulkan dari mengkonsumsi produk.

2. Social value, yaitu kegunaan yang didapatkan dari produk untuk meningkatkan konsep diri sosial konsumen.

3. Quality/performance value, yakni utilitas yang didapatkan dari produk dikarenakan reduksi biaya jangka pendek dan biaya jangka panjang.

4. Price/value of money, yakni utilitas yang diperoleh dari persepsi terhadap kualitas dan kinerja yang diharapkan atas produk. 
Kerangka Pikir

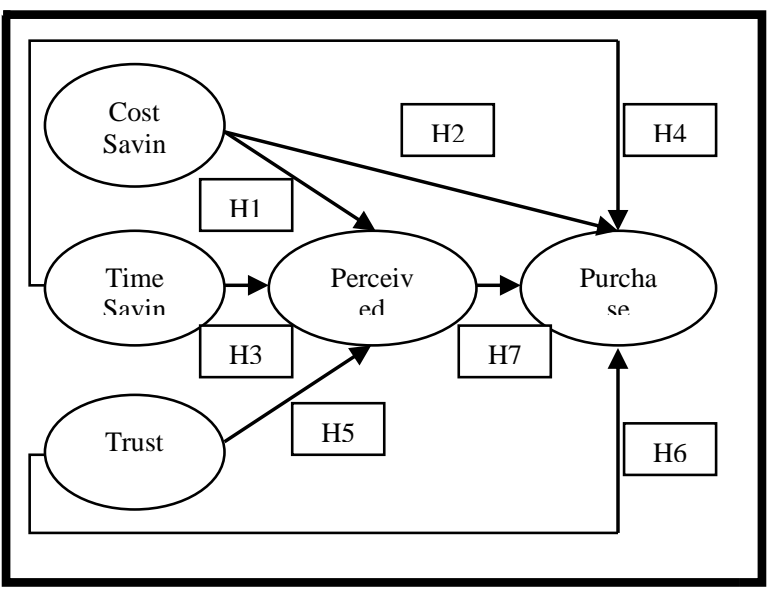

Sumber dari penelitian (Tomas Escobar Rodriguez dan Rocio Bonson Fernandez, 2017).

\section{METODE}

Penelitian ini dilakukan terhadap konsumen Minuman Tradisional Wedang Uwuh di Imogiri Bantul Yogyakarta. Populasi dalam penelitian ini yaitu konsumen yang mengkonsumsi produk Minuman Tradisional Wedang Uwuh, yang berarti wilayah generalisasinya adalah hanya pada lingkup Imogiri Bantul Yogyakarta. Untuk menentukan sampel, penelitian menggunakan kuesioner. Sampel penelitian ini didapatkan melalui kuesioner yang dibagikan oleh peneliti kepada responden konsumen Minuman Tradisional Wedang Uwuh di Imogiri Bantul Yogyakarta. Teknik pengambilan sampel yaitu dengan menyebarkan kuesioner. Anggota sampel yang digunakan adalah 100 responden.

\section{ANALISIS DAN PEMBAHASAN}

Tabel 1 Karakteristik responden berdasarkan jenis kelamin

\begin{tabular}{lrrrr}
\hline \multicolumn{5}{c}{ Jenis kelamin } \\
\hline & Frequency & Percent & $\begin{array}{c}\text { Valid } \\
\text { Percent }\end{array}$ & $\begin{array}{c}\text { Cumulative } \\
\text { Percent }\end{array}$ \\
\hline Valid laki-laki & 89 & 89,0 & 89,0 & 89,0 \\
& 11 & 11,0 & 11,0 & 100,0 \\
perempuan & 100 & 100,0 & 100,0 & \\
Total & \multicolumn{3}{c}{ Sumber: Data primer, diolah tahun 2020 }
\end{tabular}

Berdasarkan tabel 1 diketahui bahwa jumlah responden laki-laki (89\%) lebih banyak dibandingkan perempuan dengan presentase (11\%). Hal ini dikarenakan laki-laki lebih suka meminum minuman tradisional wedang uwuh.

Tabel 2 Karakteristik responden berdasarkan umur

\begin{tabular}{|c|c|c|c|c|c|}
\hline \multicolumn{6}{|c|}{ Umur } \\
\hline & & Frequency & Percent & Valid Percent & Cumulative Percent \\
\hline Valid & $17-26 \mathrm{TH}$ & 20 & 20,0 & 20,0 & 20,0 \\
\hline & 27-36TH & 25 & 25,0 & 25,0 & 25,0 \\
\hline & $37-46 \mathrm{TH}$ & 20 & 20,0 & 20,0 & 55,0 \\
\hline & $>50 \mathrm{TH}$ & 35 & 35,0 & 35,0 & 100,0 \\
\hline & Total & 100 & 100,0 & 100,0 & \\
\hline
\end{tabular}

Sumber: Data primer, diolah tahun 2020 
Berdasarkan tabel 2 dapat dilihat bahwa mayoritas responden pada penelitian ini berumur $>50$ tahun dengan presentase $(35 \%)$, hal ini menunjukkan bahwa orang tua lebih suka memimun minuma tradisional wedang uwuh dari pada para remaja.

Tabel 3 Karakteristik responden berdasarkan penghasilan

\begin{tabular}{llrrrr}
\hline \multicolumn{5}{c}{ Penghasilan } \\
\hline Valid & Frequency & Percent & Valid Percent & Cumulative Percent \\
\cline { 2 - 5 } & 20 & 20,0 & 20,0 & 20,0 \\
& Rp 1.000.000 - Rp 2.000.000 & 65 & 65,0 & 65,0 & 65,0 \\
& Rp 2.000.001 - Rp 3.000.000 & 15 & 15,0 & 15,0 & 20,0 \\
Rp 3.000.001 - Rp 4.000.000 & 5 & 5,0 & 5,0 & 100,0 \\
& Total & 100 & 100,0 & 100,0 & \\
\hline
\end{tabular}

Sumber: Data primer, diolah tahun 2020

Berdasarkan tabel 3 dapat dilihat bahwa mayoritas responden pada penelitian ini memiliki penghasilan Rp 1.000.000 - Rp 2.000.000 dengan presentase (65\%), hal ini menunjukkan bahwa masyarakat kelas menengah yang lebih menyukai minuman tradisional wedang uwuh.

Tabel 4 Karakteristik responden berdasarkan jenis pekerjaan

\begin{tabular}{llcccc}
\hline \multicolumn{5}{c}{ Jenis Pekerjaan } \\
\hline Valid & Frequency & Percent & Valid Percent & Cumulative Percent \\
\cline { 2 - 5 } & Pelajar/Mahasiswa & 20 & 20,0 & 20,0 & 20,0 \\
& PNS/TNI/BUMN & 15 & 15,0 & 15,0 & 15,0 \\
& Wiraswasta/Pengusaha & 25 & 25,0 & 25,0 & 65,0 \\
& Lainnya & 40 & 40,0 & 40,0 & 100,0 \\
& Total & 100 & 100,0 & 100,0 & \\
\hline
\end{tabular}

Sumber: Data primer, diolah tahun 2020

Berdasarkan tabel 4 dapat diketahui bahwa mayoritas responden pada penelitian ini memiliki pekerjaan lainnya, atau lebih spesifiknya ada yang menjadi petani, pekebun, peternak, dan lain sebagainya yaitu sebanyak 40 orang dengan presentase (40\%), hal ini dikarenakan minuman tradisional wedang uwuh dijual di pasar tradisional sehingga mayoritas konsumennya adalah masyarakat sekitar.

\begin{tabular}{|c|c|c|c|c|c|c|}
\hline \multicolumn{7}{|c|}{$\begin{array}{c}\text { Tabel } 5 \text { Hasil Uji Regresi Linier } 1 \\
\text { Coefficients }^{\text {a }}\end{array}$} \\
\hline & & \multicolumn{2}{|c|}{$\begin{array}{l}\text { Unstandardized } \\
\text { Coefficients }\end{array}$} & \multirow{2}{*}{$\begin{array}{c}\text { Standardized } \\
\text { Coefficients } \\
\text { Beta }\end{array}$} & \multirow[b]{2}{*}{$\mathrm{T}$} & \multirow[b]{2}{*}{ Sig. } \\
\hline \multicolumn{2}{|c|}{ Model } & $\mathrm{B}$ & Std. Error & & & \\
\hline \multirow[t]{4}{*}{1} & (Constant) & $-2,045$ & 2,632 & &,- 777 & ,439 \\
\hline & CSAV &, 777 & ,137 & ,486 & 5,670 &, 000 \\
\hline & TSAV & ,442 &, 181 & , 240 & 2,434 &, 017 \\
\hline & $\mathrm{T}$ & ,217 & ,098 & , 180 & 2,224 & ,029 \\
\hline
\end{tabular}

a. Dependent Variable: PV

Sumber: Data primer, diolah tahun 2020

Berdasarkan tabel di atas diatas, nilai signifikan dari ketiga variabel independen CSAV adalah 0,000, TSAV adalah 0,017 dan T adalah 0,029 yang berarti lebih kecil dari $\alpha=5 \%$ atau 0,05 maka dapat disimpulkan bahwa regresi model 1 yakni variabel cost 
saving, time saving, dan trust berpengaruh signifikan terhadap perceived value. Dan diperoleh persamaan regresi linier sebagai berikut:

$\mathrm{Z}=0,486 \mathrm{CSAV}+0,240 \mathrm{TSAV}+0,180 \mathrm{~T}+\mathrm{e}$

\section{Tabel 6 Hasil Uji Regresi Linier 2}

\begin{tabular}{|c|c|c|c|c|c|c|}
\hline \multirow[b]{2}{*}{ Mode } & & \multicolumn{2}{|c|}{$\begin{array}{l}\text { Unstandardized } \\
\text { Coefficients }\end{array}$} & \multirow{2}{*}{$\begin{array}{l}\text { Standardized Coefficients } \\
\text { Beta }\end{array}$} & \multirow[b]{2}{*}{$\mathrm{T}$} & \multirow[b]{2}{*}{ Sig. } \\
\hline & & B & Std. Error & & & \\
\hline \multirow[t]{5}{*}{1} & (Constant) & 8,980 & 2,605 & & 3,447 &, 001 \\
\hline & CSAV & ,329 & ,156 & 201 & 2,106 & ,038 \\
\hline & TSAV & ,658 & , 184 & ,350 & 3,572 & ,001 \\
\hline & $\mathrm{T}$ &,- 016 & ,099 &,- 013 &,- 165 & ,869 \\
\hline & PV & 349 & ,101 &, 341 & 3,465 & ,001 \\
\hline
\end{tabular}

a. Dependent Variable: PI

Sumber: Data primer, diolah tahun 2020

Berdasarkan tabel di atas menunjukkan bahwa nilai signifikan dari variabel independen CSAV, TSAV, T, dan PV masing-masing adalah 0,038, 0,001, 0,869 dan 0,001 untuk variabel CSAV, TSAV, dan PV memiliki nilai signifikan lebih kecil dari $\alpha=$ $5 \%$ atau 0,05 sedangkan variabel T memiliki nilai signifikansi lebih besar dari $\alpha=5 \%$ atau 0,05 maka dapat disimpulkan bahwa regresi model 2, yakni variabel cost saving, time saving, dan perceived value berpengaruh signifikan terhadap purchase intention. Sedangkan variabel trust tidak berpengaruh terhadap purchase intention pada regresi model 2.

Persamaan regresi linier:

$$
\mathrm{Y}=0,201 \mathrm{CSAV}+0,350 \mathrm{TSAV}+(-0,013) \mathrm{T}+0,341 \mathrm{PV}+\mathrm{e}
$$

\section{KESIMPULAN DAN SARAN}

Berdasarkan hasil pembahasan pada bab sebelumnya dapat disimpulkan sebagai berikut:

a. Cost saving berpengaruh positif terhadap perceived value dan purchase intention. Terjangkaunya biaya yang dikeluarkan oleh konsumen untuk membeli minuman tradisional wedang uwuh di Imogiri Bantul Yogyakarta dan yang di cirikan harga murah, mudah didapatkan dan secara bertransaksi tidak sulit membuat konsumen memiliki niat untuk membeli produk tersebut.

b. Time Saving berpengaruh positif terhadap terhadap perceived value dan purchase intention. Kemampuan produsen dalam mengendalikan waktu produksi serta perencanaan yang matang, membuat konsumen merasa puas terhadap produk minuman tradisional wedang uwuh di Imogiri Bantul Yogyakarta.

c. Trust berpengaruh positif berpengaruh negatif terhadap purchase intention. Kepercayaan konsumen terhadap produk yang dijual merupakan sebuah kunci dari penjualan, adanya jaminan kepuasan, perhatian terhadap konsumen dan kejelasan informasi dalam menjual sebuah produk menjadi keunggulan bagi produk minuman tradisional wedang uwuh di Imogiri Bantul Yogyakarta untuk membentuk persepsi nilai dari para pelanggan tetapi tidak berpengaruh terhadap minat konsumen untuk membeli produk minuman tradisional wedang uwuh di Imogiri Bantul Yogyakarta.

d. Perceived value berpengaruh positif terhadap purchase intention. Dengan membangun persepsi nilai kebermanfaatan minuman tradisional wedang uwuh di Imogiri Bantul Yogyakarta dapat membuat konsumen memiliki minat beli, merekemondasikan kepada teman sejawatnya untuk membeli produk minuman tradisional wedang uwuh di Imogiri Bantul Yogyakarta. 
Berdasarkan hasil temuan tersebut diharapkan produsen minuman tradisional wedang uwuh di Imogiri Bantul Yogyakarta dapat mempertahankan serta meningkatkan cost saving, time saving, dan trust untuk membentuk persepsi perceived value konsumen yang berdampak pada purchase intention terhadap minuman tradisional wedang uwuh di Imogiri Bantul Yogyakarta.

\section{SARAN}

Bagi Produsen minuman tradisional wedang uwuh di Imogiri Bantul Yogyakarta

a. Cost saving berpengaruh positif terhadap perceived value, maka produsen harus meningkatkan purchase intention dengan cara meningkatkan penghematan biaya produksi. Semakin hemat biaya produksi maka semakin meningkat perceived value terhadap purchase intention.

b. Time Saving berpengaruh positif terhadap perceived value, maka perusahaan harus meningkatkan purchase intention dengan cara meningkatkan penghematan waktu pada minuman tradisional wedang uwuh di Imogiri Bantul Yogyakarta dan semakin meningkat time saving maka semakin meningkat perceived value terhadap purchase intention.

c. Trust berpengaruh positif terhadap perceived value, maka perusahaan harus meningkatkan perceived value dengan cara meningkatkan kepercayaan konsumen terhadap kualitas produk minuman tradisional wedang uwuh di Imogiri Bantul Yogyakarta dan semakin meningkat trust konsumen terhadap produk minuman tradisional wedang uwuh di Imogiri Bantul Yogyakarta maka akan meningkatkan perceived value.

Bagi Akademis

a. Dapat dijadikan sebagai bahan pertimbangan, atau referens dengan variabel penelitian cost saving, time saving, trust, perceived value dan purchase intention.

Untuk penelitian selanjutnya dalam bidang yang sama diharapkan dapat mencari variabelvariabel lain selain cost saving, time saving, trust, perceived value dan purchase intention. Seperti Service, price, promotion dan place..

\section{DAFTAR PUSTAKA}

Article, O. (2017). Analysing online purchase intention in Spain: 599-622. https://doi.org/10.1007/s10257-016-0319-6

Basu Swastha dan Irwan, 2001. Management Pemasaran Modern, Liberty. Yogyakarta.

Choirunnisa dan Anjar Priyono. (2018). Interaksi Antara Perceived Value, Transaction Cost, dan Repurchase Intention Dalam Transaksi On-line. Jurnal Manajemen Vol. 12 .

Din, M., \& Rahman, F. (2013). Analisis Eco-label terhadap Minat Beli Konsumen pada Minuman Kemasan Produk Minuman Tahun 2004-2015. 927-937.

Disa, S. M., \& Kesuma, T. M. (2017). Pengaruh Persepsi Risiko, Persepsi Manfaat Dan Kepercayaan Terhadap Niat Pembelian Konsumen Di Portal E-Commerce Zalora.Co.Id. Jurnal Iilmiah Mahasiswa Ekonomi Manajemen, Vol. 2(1), Hal. 202223.

http://wedanguwuhherbal.wordpress.com/2013/01/18/apa-itu-wedang-uwuh/ 
Huang, K. Y., Nambisan, P., \& Uzuner, Ö. (2010). Informational support or emotional support: Preliminary study of an automated approach to analyze online support community contents. ICIS 2010 Proceedings - Thirty First International Conference on Information Systems.

Indiani, N. L. P., Rahyuda, I. K., Kerti Yasa, N. N., \& Sukaatmadja, I. P. G. (2015). Perceived Risk and Trust as Major Determinants of Actual Purchase, Transcending The Influence of Intention. ASEAN Marketing Journal, 7(1), 1-13. https://doi.org/10.21002/amj.v7i1.4601

Kotler, Philip, dan Gary Amstrong, ( 2009). Prinsip- Prinsip Pemasaran.

Lidyawati.1998. Hubungan antara Intensitas Menonton Iklan di Televisi dengan Perilaku Konsumtif. Skripsi (tidak diterbitkan). Surakarta: Fakultas Psikoli UMS.

Putra, K., \& Indriyani, R. (2018). Pengaruh Kepercayaan Pelanggan Terhadap Kepuasan Pelanggan Cv Mitra Perkasa Utomo. Jurnal Manajemen Dan Bisnis, 7(2016), 2. publication.petra.ac.id/index.php/manajemen-

bisnis/article/download/7800/7033\%0A

Putu Rustami, I Ketut Kirya, \& Wayan Cipta. (2014). Pengaruh Biaya Produksi, Biaya Promosi, Dan Volume Penjualan Terhadap Laba Pada Perusahaan Kopi Bubuk Banyuatis.

Schiffman dan Kanuk. (2007). Perilaku Konsumen Edisi Kedua. Jakarta: PT. Indeks Gramedia.

Srijanti, P., \& P. Artiningrum. (2007). Etika membangun sikap profesionalisme sarjana. Jakarta: Graha Ilmu.

Suarjana, I Kadek \& Sri Suprapti, N. W. (2018). Fakultas Ekonomi dan Bisnis Universitas Udayana , Bali, Indonesia Pada era teknologi komunikasi yang berkembang sangat pesat, masyarakat membutuhkan akses internet yang cepat, mudah, dan murah. Baik pengguna internet maupun volume penggunaannya makin. 7(4), 1920-1949.

Sugiyono. (2013). Metode Penelitian Manajemen. Jakarta: Alfabeta, First Edition.

Sulastri, S. N. dan A. (2018). Lifestyle, Perceived Value dan Customer Value Terhadap Minat Beli. Jurnal Ekspansi, 10(2), 147-162.

Wulandari, NL. Ekawati NW. 2015. Peran Kepercayaan dalam Memediasi Persepsi Nilai terhadap Niat Beli Produk Ramah Lingkungan. E-Jurnal Manajemen Unud, Vol. 4, No. 7, 2095-2109. 